\title{
Characteristics of Patients with Acute Flaccid Myelitis, United States, 2015-2018
}

\author{
Nilay McLaren, Adriana Lopez, Sarah Kidd, John X. Zhang, W. Allan Nix, \\ Ruth Link-Gelles, Adria Lee, Janell A. Routh
}

\section{Medscape ACTIVITY}

In support of improving patient care, this activity has been planned and implemented by Medscape, LLC and Emerging Infectious Diseases. Medscape, LLC is jointly accredited by the Accreditation Council for Continuing Medical Education (ACCME), the Accreditation Council for Pharmacy Education (ACPE), and the American Nurses Credentialing Center (ANCC), to provide continuing education for the healthcare team.

Medscape, LLC designates this Journal-based CME activity for a maximum of 1.00 AMA PRA Category 1 Credit(s) ${ }^{\mathrm{TM}}$ Physicians should claim only the credit commensurate with the extent of their participation in the activity.

Successful completion of this CME activity, which includes participation in the evaluation component, enables the participant to earn up to $1.0 \mathrm{MOC}$ points in the American Board of Internal Medicine's (ABIM) Maintenance of Certification (MOC) program. Participants will earn MOC points equivalent to the amount of CME credits claimed for the activity. It is the CME activity provider's responsibility to submit participant completion information to ACCME for the purpose of granting ABIM MOC credit.

All other clinicians completing this activity will be issued a certificate of participation. To participate in this journal CME activity: (1) review the learning objectives and author disclosures; (2) study the education content; (3) take the post-test with a $75 \%$ minimum passing score and complete the evaluation at http://www.medscape.org/journal/eid; and (4) view/print certificate. For CME questions, see page 399.

Release date: January 15, 2020; Expiration date: January 15, 2021

Learning Objectives

Upon completion of this activity, participants will be able to:

- Compare the clinical and laboratory characteristics of AFM cases reported in the United States during peak vs. nonpeak years from 2015 through 2018

- Compare the clinical and laboratory characteristics of AFM cases reported in the United States during peak years 2016 vs. 2018

- Describe the clinical and public health significance of differences in the clinical and laboratory characteristics of AFM cases reported in the United States during peak vs. nonpeak years from 2015 through 2018

\section{CME Editor}

Kristina B. Clark, PhD, Copyeditor, Emerging Infectious Diseases. Disclosure: Kristina B. Clark, PhD, has disclosed no relevant financial relationships.

\section{CME Author}

Laurie Barclay, MD, freelance writer and reviewer, Medscape, LLC. Disclosure: Laurie Barclay, MD, has disclosed no relevant financial relationships.

\section{Authors}

Disclosures: Nilay McLaren; Adriana Lopez, MHS; Sarah Kidd, MD, MPH; John X. Zhang, PhD; W. Allan Nix, BS;

Ruth Link-Gelles, PhD, MPH; Adria Lee, MSPH; and Janell A. Routh, MD, MHS, have disclosed no relevant financial relationships.

Observed peaks of acute flaccid myelitis (AFM) cases have occurred biennially since 2014 in the United States. We aimed to determine if AFM etiology differed between peak and nonpeak years, considering that clinical features of AFM differ by virus etiology. We compared clinical and laboratory characteristics of AFM cases that occurred

Author affiliation: Centers for Disease Control and Prevention, Atlanta, Georgia, USA

DOI: https://doi.org/10.3201/eid2602.191453

during peak (2016 and 2018, $\mathrm{n}=366)$ and nonpeak (2015 and 2017, $n=50$ ) years. AFM patients in peak years were younger (5.2 years) than those in nonpeak years (8.3 years). A higher percentage of patients in peak years than nonpeak years had pleocytosis ( $86 \%$ vs. $60 \%)$, upper extremity involvement (33\% vs. $16 \%)$, and an illness preceding limb weakness (90\% vs. $62 \%)$ and were positive for enterovirus or rhinovirus RNA (38\% vs. $16 \%$ ). Enterovirus D68 infection was associated with AFM only in peak years. Our findings suggest AFM etiology differs between peak and nonpeak years.
\end{abstract}


A cute flaccid myelitis (AFM) is a clinical syndrome characterized by the acute onset of flaccid limb weakness accompanied by spinal cord gray matter lesions. AFM is a known complication of infection with certain viruses, including polioviruses, nonpolio enteroviruses, flaviviruses, herpesviruses, and adenoviruses (1-7). In the early 1950s, outbreaks of poliovirus caused $>15,000$ cases of paralysis each year in the United States, but after the introduction of poliovirus vaccines and the elimination of poliovirus in the United States, AFM caused by poliovirus became much less common (8). However, sporadic, poliovirus-negative cases continued to occur (9).

In August 2014, an unusual cluster of AFM in children was identified in Colorado (10). National surveillance was initiated in 2015 and subsequently led to the identification of heightened activity in 2016 and 2018; during these years, peak illness onset occurred during August-October. In contrast, in 2015 and 2017, the number of AFM cases remained low and did not vary by season (11). National experts agree that the AFM epidemiology observed in 2014 is new; this alternating pattern of high activity one year and low activity the next, referred to herein as peak and nonpeak years, with high activity typically in the late summer or early fall, has not been documented before 2014 (12-14) (M. Cortese, Centers for Disease Control and Prevention [CDC], Atlanta, GA, USA, pers. comm., 2017 Sep 27). This change suggests the emergence (beginning in 2014) of either a new cause of AFM or a known cause of AFM with a new epidemiologic pattern.

Determining the cause or causes of the biennial increases in AFM cases has implications for the development of treatment and prevention strategies. However, pathogen-specific laboratory testing has yielded limited insight into the underlying cause of this new epidemiology. Different viruses known to be associated with AFM development have been shown to produce distinctive sets of clinical features $(15,16)$. If a single pathogen is responsible for most AFM cases in peak years, cases of illness onset in these years probably would have clinical manifestations distinct from those of illness onset in nonpeak years, when the etiology of cases is likely more mixed. We compared demographic, clinical, and laboratory characteristics of AFM cases in peak versus nonpeak years to evaluate this hypothesis.

\section{Methods}

\section{Reporting and Classification}

Beginning in August 2014, CDC received reports of patients meeting the clinical criterion for AFM (i.e., acute onset of flaccid limb weakness) through local and state health departments. A panel of expert neurologists classified these patients according to the standardized case definition published by the Council of State and Territorial Epidemiologists in 2015 (17). We defined a confirmed case as an illness in a patient who met the clinical criterion and had magnetic resonance imaging (MRI) showing a spinal cord lesion largely restricted to the gray matter and spanning $\geq 1$ spinal segment. Our analysis includes only confirmed AFM cases in patients $<22$ years of age and is limited to 4 complete years of AFM surveillance (January 1, 2015-December 31, 2018).

\section{Laboratory Testing}

CDC staff requested sterile site (e.g., blood, serum, and cerebrospinal fluid [CSF]) and nonsterile site (e.g., respiratory and fecal) specimens from each patient and tested these specimens using algorithms described previously $(18,19)$. With specimens from 2015 and 2016, and starting in September 2018 with all received specimens, CDC staff tested for enterovirus/ rhinovirus RNA using a 5' nontranslated regiontargeted pan-Enterovirus real-time reverse transcription PCR assay (genus-level detection) and typed those that were positive. For specimens collected during January 2017-August 2018, only the specimens that had tested positive for enterovirus/rhinovirus RNA at an outside institution were requested by CDC staff for testing and typing. In our analysis, we report only the results from CDC laboratory testing.

\section{Data Analysis}

To assess trends in AFM activity over time, we assigned patients with confirmed cases to an epidemiologic week according to their date of onset of limb weakness. We compared cases of patients having AFM onset in peak years (i.e., 2016 and 2018) with those of patients having AFM onset in nonpeak years (i.e., 2015 and 2017) and compared cases between the 2 peak years (2016 vs. 2018). We analyzed the demographics, clinical characteristics, and laboratory results of AFM patients that had been systematically collected across all 4 years of surveillance. We defined AFM cases as severe if they included all 3 of the following clinical characteristics: respiratory distress requiring mechanical ventilation to manage, symptomatic cranial nerve involvement, and paralysis of all 4 limbs. We defined CSF pleocytosis as a leukocyte count of $>5$ cells $/ \mathrm{mm}^{3}$.

We entered data into a Microsoft Access (for 2015-2017 data; https://www.microsoft.com) or REDCap (for 2018 data; https: / www.project-redcap. org) database and performed descriptive analyses using R Studio version 3.4.1 (https://rstudio.com). 
Denominators varied slightly by variable because of missing data. We assessed differences in categorical variables using Fisher exact test and compared medians using the Kruskal-Wallis test. We considered $p$ values $<0.05$ statistically significant.

CDC staff determined that we collected data through the standardized public health surveillance system and not through research involving humans. Thus, this study did not require institutional review board clearance.

\section{Results}

Of 750 suspected AFM cases reported to the CDC during 2015-2018, a total of $416(\mathrm{n}=18$ in 2015, $\mathrm{n}=$ 143 in 2016, $n=32$ in 2017, and $n=223$ in 2018) occurred in patients $<22$ years of age and were classified as confirmed. Cases in patients of this age group represented $95 \%$ of all confirmed cases. The median age of patients with confirmed cases was 5.4 (range $0.3-21.9$, interquartile range $3.2-8.7$ ) years; $60 \%$ were male. In peak years (2016 and 2018), the increase in confirmed AFM cases started in August, and for both peak years, most patients with confirmed cases had illness onset during August-October (Figure).

When comparing the characteristics of confirmed AFM cases from peak years (2016 and 2018) and nonpeak years (2015 and 2017), we found that patient median age was significantly lower in peak years (5.2 [range 0.4-21.9] years of age) than nonpeak years (8.3 [range 0.3-20.2] years of age; $p=0.02$ ) (Table 1 ). The limbs affected by AFM also varied; during peak years, a higher percentage of cases involved upper extremity weakness only (33\% vs. $16 \%$; $p=0.01)$ and a lower percentage involved lower extremity weakness only ( $13 \%$ vs. $32 \%$; $<<0.001)$. During peak years, fewer cases could be classified as severe ( $2 \%$ vs. $18 \%$; $\mathrm{p}<0.001)$. The percentage of AFM patients who had a preceding illness (i.e., any fever or respiratory illness) during the 4 weeks before limb weakness onset was higher in peak years $(90 \%)$ than nonpeak years (62\%; $\mathrm{p}<0.001)$, and CSF pleocytosis was more common among AFM patients in peak years (86\%) than in nonpeak years $(60 \% ; p<0.001)$. The percentage of patients with a specimen positive for enterovirus/ rhinovirus RNA was significantly greater in peak years $(38 \%)$ than nonpeak years $(16 \% ; p=0.02)$. During peak years, a greater percentage of enterovirus/ rhinovirus-positive specimens was positive for enterovirus D68 (EV-D68) RNA ( $54 \%$ vs. 0\%; p = 0.02).

To evaluate whether the characteristics of cases from nonpeak months were masking the characteristics of cases from peak months, which we hypothesized to be associated with a single pathogen, we conducted a sensitivity analysis comparing cases in peak months (August-October) from peak years (2016 and 2018) with cases from all nonpeak months (January-July and November-December of 2016 and 2018, JanuaryDecember of 2015 and 2017) (Table 2). Most variables remained significant in the sensitivity analysis. However, the difference in median age between peak and nonpeak years was no longer significant. The percentage of cases with pleocytosis remained significantly higher in peak months than nonpeak months ( $\mathrm{p}<0.001)$, and in this analysis, the median cell count was also significantly higher in cases in peak months $\left(88\right.$ cells $\left./ \mathrm{mm}^{3}\right)$ than in cases in nonpeak months ( 44 cells $/ \mathrm{mm}^{3 ;} \mathrm{p}<0.001$ ). The percentage of cases with a specimen positive for enterovirus or rhinovirus RNA was no longer significantly greater in peak months $(38 \%)$ than nonpeak months $(31 \% ; \mathrm{p}=0.25)$. The percentage of EV-D68-positive cases was also no longer significantly greater in peak months (58\%) than nonpeak months (37\%; $\mathrm{p}=0.08)$.

Patients with illness onset in 2018 and illness onset in 2016 were clinically similar to each other (Table

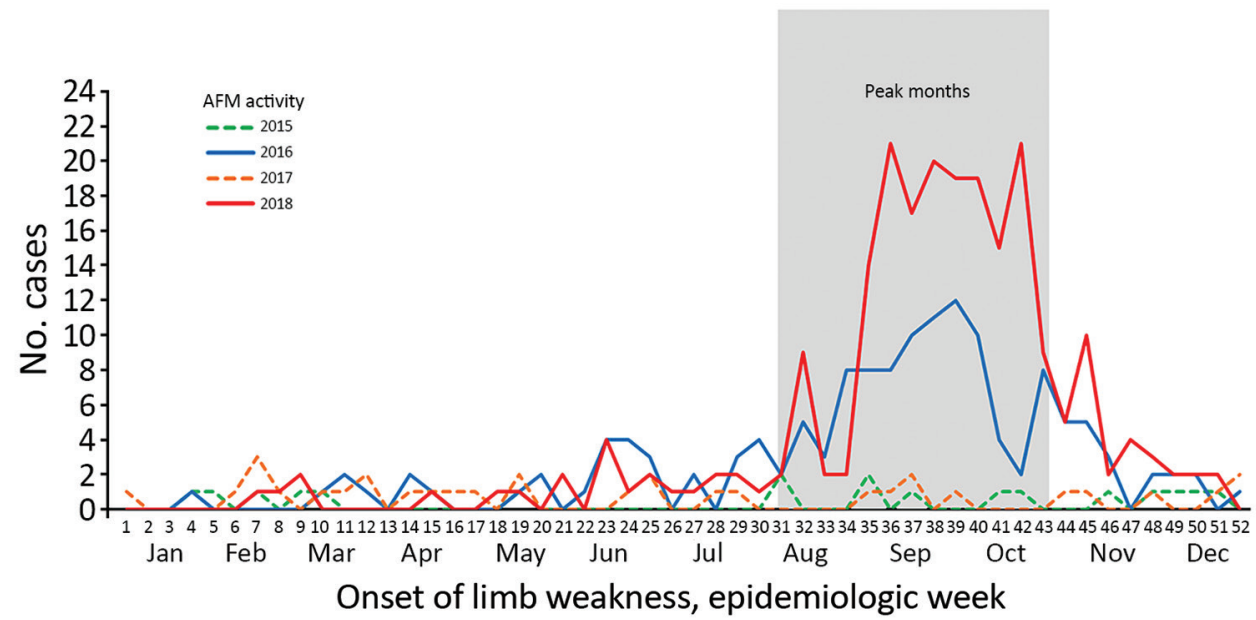

Figure. Confirmed AFM cases in patients $<22$ years of age by week of limb weakness onset, United States, January 2015December 2018. AFM, acute flaccid myelitis. 
Table 1. Descriptive characteristics of confirmed AFM cases in patients $<22$ years of age from peak years versus nonpeak years, United States, January 2015-December 2018*

\begin{tabular}{|c|c|c|c|}
\hline Characteristic & Peak years, $n=366 \dagger$ & Nonpeak years, $n=50 \ddagger$ & $\mathrm{p}$ value \\
\hline Age, y, median (range) [IQR] & $5.2(0.4-21.9)[3.2-8.0]$ & $8.3(0.3-20.2)[3.9-11.9]$ & 0.02 \\
\hline \multicolumn{4}{|l|}{ Sex } \\
\hline M & $217 / 366(59)$ & $32 / 50(64)$ & 0.54 \\
\hline $\mathrm{F}$ & $149 / 366(41)$ & $18 / 50(36)$ & 0.54 \\
\hline Lumbar puncture & $343 / 363(94)$ & $48 / 49(98)$ & 0.84 \\
\hline Pleocytosis $\S$ & $283 / 328(86)$ & $28 / 47(60)$ & $<0.001$ \\
\hline CSF, cells $/ \mathrm{mm}^{3}$, median (range) [IQR] & $75(0-3,261)[24-150]$ & $32(0-1,081)[3-168]$ & 0.07 \\
\hline Upper extremity involvement only & $121 / 366(33)$ & $8 / 50(16)$ & 0.01 \\
\hline Lower extremity involvement only & $49 / 366(13)$ & $16 / 50(32)$ & $<0.001$ \\
\hline Paralysis of all 4 limbs & $101 / 366(28)$ & $24 / 50(48)$ & 0.005 \\
\hline Severe AFMT & $9 / 366(2)$ & $9 / 50(18)$ & $<0.001$ \\
\hline Cranial nerve lesion & $96 / 366(26)$ & $10 / 50(20)$ & 0.39 \\
\hline \multicolumn{4}{|l|}{ IIIness within previous 4 weeks } \\
\hline Any fever & $258 / 358(72)$ & $27 / 49(55)$ & 0.02 \\
\hline Any respiratory illness & $282 / 360(78)$ & $21 / 49(43)$ & $<0.001$ \\
\hline Any gastrointestinal illness & $111 / 344(32)$ & $12 / 34(35)$ & 0.24 \\
\hline Any respiratory illness or fever & $328 / 366(90)$ & $31 / 50(62)$ & $<0.001$ \\
\hline Enterovirus/rhinovirus RNA positive & $98 / 258(38)$ & $5 / 31(16)$ & 0.02 \\
\hline Enterovirus D68 & $53 / 98(54)$ & $0 / 5$ & 0.02 \\
\hline Enterovirus A71 & $13 / 98(13)$ & $1 / 5(20)$ & 0.59 \\
\hline \multicolumn{4}{|c|}{$\begin{array}{l}\text { *Values are no./total (\%), except where indicated otherwise. AFM, acute flaccid myelitis; CSF, cerebrospinal fluid; IQR, interquartile range. } \\
+2016 \text { and } 2018 . \\
\ddagger 2015 \text { and } 2017 \text {. } \\
\text { §Defined as leukocyte count }>5 \text { cells } / \mathrm{mm}^{3} \text {. } \\
\text { IDefined as AFM cases of respiratory distress that required mechanical ventilation, cranial nerve involvement, and paralysis of all } 4 \text { limbs. }\end{array}$} \\
\hline
\end{tabular}

3), with a few notable exceptions. Cranial nerve lesions were less common in AFM patients in 2018 (19\%) than in AFM patients in 2016 (37\%; $<<0.001)$. More cases in $2016(6 \%)$ than $2018(0 \%$; p<0.001) were classified as severe AFM. Compared with AFM patients in 2016, more AFM patients in 2018 were reported to have an illness within the 4 weeks preceding the onset of limb weakness: any fever (68\% in 2016 vs. $75 \%$ in 2018; p<0.001), respiratory illness (76\% in 2016 vs. $80 \%$ in 2018; $\mathrm{p}=0.01)$, or gastrointestinal illness $(26 \%$ in 2016 vs. $36 \%$ in 2018; $p=0.002$ ). The percentage of confirmed AFM cases positive for enterovirus/rhinovirus RNA was similar in both peak years. Among all enterovirus/rhinovirus-positive specimens, EV-D68positive specimens were more common in 2016 (71\%) than in $2018(45 \% ; p=0.02)$. However, AFM patients

Table 2. Descriptive characteristics of confirmed AFM cases in patients <22 years of age from peak months versus nonpeak months, United States, January 2015-December 2018*

\begin{tabular}{|c|c|c|c|}
\hline Characteristic & All peak months, $n=268 \dagger$ & All nonpeak months, $\mathrm{n}=148 \ddagger$ & $\mathrm{p}$ value \\
\hline Age, y, median (range) [IQR] & $5.2(0.5-21.9)[3.3-7.8]$ & $5.7(0.3-21.9)[3.2-10.6]$ & 0.18 \\
\hline \multicolumn{4}{|l|}{ Sex } \\
\hline M & $159 / 268(59)$ & $90 / 148(61)$ & 0.83 \\
\hline $\mathrm{F}$ & 109/268 (41) & $58 / 148(39)$ & 0.83 \\
\hline Lumbar puncture & $251 / 267(94)$ & $140 / 145(97)$ & 0.35 \\
\hline Pleocytosis§ & $212 / 239(89)$ & $99 / 136(73)$ & $<0.001$ \\
\hline $\mathrm{CSF}$, cells $/ \mathrm{mm}^{3}$, median (range) [IQR] & $88(0-814)[30-154]$ & $44(0-3,261)[4-118]$ & $<0.001$ \\
\hline Upper extremity involvement only & $95 / 268(35)$ & $34 / 148(23)$ & 0.01 \\
\hline Lower extremity involvement only & $29 / 268(11)$ & $36 / 148(24)$ & 0.001 \\
\hline Paralysis of all 4 limbs & $67 / 268(25)$ & $58 / 148(39)$ & 0.004 \\
\hline Severe AFMT & $5 / 268(2)$ & $13 / 148(9)$ & 0.002 \\
\hline Cranial nerve lesion & $72 / 268(27)$ & $34 / 148(23)$ & 0.41 \\
\hline \multicolumn{4}{|l|}{ Illness within previous 4 weeks } \\
\hline Any fever & $201 / 262(77)$ & $84 / 145(58)$ & $<0.001$ \\
\hline Any respiratory illness & $214 / 264(81)$ & $89 / 145(61)$ & $<0.001$ \\
\hline Any gastrointestinal illness & $80 / 256(31)$ & $43 / 122(35)$ & 0.46 \\
\hline Any respiratory illness or fever & $246 / 268(92)$ & $113 / 148(76)$ & $<0.001$ \\
\hline Enterovirus/rhinovirus RNA positive & $73 / 192(38)$ & $30 / 97(31)$ & 0.25 \\
\hline Enterovirus D68 & $42 / 73(58)$ & $11 / 30(37)$ & 0.08 \\
\hline Enterovirus A71 & $6 / 73(8)$ & $8 / 30(27)$ & 0.02 \\
\hline
\end{tabular}

${ }^{*}$ Values are no./total (\%), except where indicated otherwise. AFM, acute flaccid myelitis; CSF, cerebrospinal fluid; IQR, interquartile range. †August-October of 2016 and 2018.

†January-July and November-December of 2016 and 2018, January-December of 2015 and 2017.

§Defined as leukocyte count $>5$ cells $/ \mathrm{mm}^{3}$.

IDefined as AFM cases of respiratory distress that required mechanical ventilation, cranial nerve involvement, and paralysis of all 4 limbs. 
Table 3. Descriptive characteristics of confirmed AFM cases in patients $<22$ years of age from peak years, United States, JanuaryDecember 2016 and 2018*

\begin{tabular}{|c|c|c|c|}
\hline Characteristic & $2016, n=143$ & $2018, n=223$ & $p$ value \\
\hline Age, y, median (range) [IQR] & $5.3(0.4-21.2)[3.2-9.7]$ & $5.2(0.5-21.9)[3.2-7.8]$ & 0.43 \\
\hline \multicolumn{4}{|l|}{ Sex } \\
\hline M & $86 / 143(60)$ & $131 / 223(59)$ & 0.83 \\
\hline $\mathrm{F}$ & $57 / 143(40)$ & $92 / 223(41)$ & 0.83 \\
\hline Lumbar puncture & $135 / 140(96)$ & $208 / 223(93)$ & 0.14 \\
\hline Pleocytosis† & $114 / 135(84)$ & $169 / 208(81)$ & 0.47 \\
\hline $\mathrm{CSF}$, cells $/ \mathrm{mm}^{3}$, median (range) [IQR] & $77(0-3,261)[18-150]$ & $74(0-814)[27-152]$ & 0.22 \\
\hline Upper extremity involvement only & $48 / 143(34)$ & $73 / 223(33)$ & 0.91 \\
\hline Lower extremity involvement only & $25 / 143(17)$ & $24 / 223(11)$ & 0.08 \\
\hline Paralysis of all 4 limbs & $45 / 143(31)$ & $56 / 223(25)$ & 0.19 \\
\hline Severe AFM & $9 / 143(6)$ & $0 / 223$ & $<0.001$ \\
\hline Cranial nerve lesion & $53 / 143(37)$ & $43 / 223(19)$ & $<0.001$ \\
\hline \multicolumn{4}{|l|}{ Illness within previous 4 weeks } \\
\hline Any fever & $93 / 137(68)$ & $165 / 221(75)$ & $<0.001$ \\
\hline Any respiratory illness & $106 / 139(76)$ & $176 / 221(80)$ & 0.01 \\
\hline Any gastrointestinal illness & $33 / 126(26)$ & $78 / 218(36)$ & 0.002 \\
\hline Any respiratory illness or fever & $122 / 143(85)$ & $206 / 223(92)$ & 0.04 \\
\hline Enterovirus/rhinovirus RNA positive & $34 / 94(36)$ & $64 / 164(39)$ & 0.69 \\
\hline Enterovirus D68 & $24 / 34(71)$ & $29 / 64(45)$ & 0.02 \\
\hline Enterovirus A71 & $2 / 34(6)$ & $11 / 64(17)$ & 0.21 \\
\hline
\end{tabular}

in 2018 (17\%) were more likely than those in 2016 (6\%; $p=0.21)$ to be positive for EV-A71 because of a geographically limited outbreak of EV-A71 in Colorado.

To determine whether the differences in case characteristics between peak years could be explained by the EV-A71 outbreak, we conducted a subanalysis in which we removed all EV-A71-positive cases. Differences in clinical characteristics between years remained unchanged; however, the percentage of cases positive for EV-D68 was no longer significantly different $(75 \%$ vs. $55 \%$; p $=0.07)$ (Table 4$)$.

\section{Discussion}

Five years of national AFM surveillance data show a seasonal, alternate-year pattern of AFM activity. The numbers of confirmed cases in peak years (2016 and 2018) was $>5$ times the numbers of cases in the previous year. Our analysis demonstrates key clinical differences between cases in peak years and nonpeak years. Patients with AFM onset in peak years were younger, more likely to have had fever or respiratory symptoms within the 4 weeks preceding AFM onset, and more likely to have pleocytosis and upper extremity weakness during hospitalization than those with AFM onset in nonpeak years. These clinical characteristics mirror the presentation of AFM described for cases of onset in 2014 (20). Patients with onset in nonpeak years were more severely affected during acute illness than those with onset in peak years. We also found differences between AFM patients with onset in 2016 and AFM patients with onset in 2018, the 2 peak years. Compared with AFM patients with onset in 2016, those with onset in 2018 were less likely to have severe disease or cranial nerve lesions and were more likely to have a preceding illness before AFM onset.

Differences in the clinical presentation of AFM between peak and nonpeak years are suggestive of differences in AFM etiologies between those years. Likewise, the clinical differences between cases occurring during peak and nonpeak years might be indicative of different virus etiologies between peak and nonpeak years. In our analysis, enterovirus positivity among AFM cases was higher in peak years than in nonpeak years, and EV-D68 was detected only in the cases occurring during peak years. Although this difference disappeared in the sensitivity analysis (suggesting that the enteroviruses circulating in peak years varies slightly by month), EVD68 detections remained exclusive to cases occurring in peak years. AFM case counts also vary slightly by month in different peak years; the escalation in cases began earlier in 2016 than they did in 2018, and the increase in case counts lasted slightly longer in 2018.

In peak years, overall enterovirus positivity among AFM cases was similar, but significant type-specific variations were noted. EV-D68 was detected more frequently in specimens from AFM patients with onset in 2016 and EV-A71 more often in those with onset in 2018. These variations might have contributed to differences in clinical characteristics seen between peak years. However, removal of EV-A71-positive cases did not eliminate the differences in clinical characteristics between peak years, suggesting that the greater number of EV-D68-positive cases in 2016 contributed to the clinical variability. Distinct AFM clinical presentations 
Characteristics of Acute Flaccid Myelitis

Table 4. Descriptive characteristics of confirmed AFM cases in patients $<22$ years of age who were negative for enterovirus $A 71$ during peak years, United States, January-December 2016 and $2018^{*}$

\begin{tabular}{|c|c|c|c|}
\hline Characteristic & $2016, n=141$ & $2018, n=212$ & $\mathrm{p}$ value \\
\hline Age, y, median (range) [IQR] & $5.4(0.4-21.2)[3.3-9.8]$ & $5.3(0.5-21.9)[3.4-7.8]$ & 0.68 \\
\hline \multicolumn{4}{|l|}{ Sex } \\
\hline M & $86 / 141(61)$ & $120 / 212(57)$ & 0.44 \\
\hline $\mathrm{F}$ & $55 / 141(39)$ & $92 / 212(43)$ & 0.44 \\
\hline Lumbar puncture & $134 / 139(96)$ & $197 / 212(93)$ & 0.13 \\
\hline Pleocytosis $\dagger$ & $113 / 132(86)$ & $158 / 184(86)$ & 1 \\
\hline CSF, cells $/ \mathrm{mm}^{3}$, median (range) [IQR] & $73(0-3,261)[18-150]$ & $73(0-814)[25.5-149]$ & 0.86 \\
\hline Upper extremity involvement only & $48 / 141(34)$ & $71 / 212(33)$ & 1 \\
\hline Lower extremity involvement only & $25 / 141(18)$ & $23 / 212(11)$ & 0.08 \\
\hline Paralysis of all 4 limbs & $44 / 141(31)$ & $50 / 212(24)$ & 0.14 \\
\hline Severe AFM $\ddagger$ & $9 / 141(6)$ & $0 / 212$ & $<0.001$ \\
\hline Cranial nerve lesion & $52 / 141(37)$ & $42 / 212(20)$ & $<0.001$ \\
\hline \multicolumn{4}{|l|}{ Illness within previous 4 weeks } \\
\hline Any fever & $91 / 135(67)$ & $154 / 210(73)$ & $<0.001$ \\
\hline Any respiratory illness & $104 / 137(76)$ & $172 / 210(82)$ & 0.004 \\
\hline Any gastrointestinal illness & $32 / 124(26)$ & $72 / 207(35)$ & 0.003 \\
\hline Any respiratory illness or fever & $120 / 141(85)$ & $195 / 212(92)$ & 0.05 \\
\hline Enterovirus/rhinovirus RNA positive & $32 / 92(35)$ & $53 / 153(35)$ & 1 \\
\hline Enterovirus D68 & $24 / 32(75)$ & $29 / 53(55)$ & 0.07 \\
\hline
\end{tabular}

have been observed for different enterovirus etiologies $(15,16)$. AFM caused by EV-A71 has been associated with myoclonus, ataxia, weakness, and autonomic instability. In an isolated outbreak in Colorado in 2018, AFM cases associated with EV-A71 were clinically distinct from those not associated with EV-A71 (15). Of note, paralytic syndrome caused by poliovirus is classically characterized by lower extremity weakness of an asymmetric distribution and a preceding mild gastrointestinal illness, features less common among AFM cases in peak years (16).

Although multiple viruses are associated with AFM, growing evidence suggests that nonpolio enteroviruses and specifically EV-D68 are linked to the changes in AFM epidemiology that started in 2014 (21,22). Enteroviruses were the most common viruses in nasopharyngeal, oropharyngeal, or fecal specimens from confirmed AFM patients identified by CDC researchers, and EV-D68 was the most frequent enterovirus typed (18-20). Unlike most other viruses known to cause AFM, enteroviruses routinely circulate and can cause outbreaks during the late summer and early fall months in the United States in a pattern corresponding with the observed seasonal AFM peaks $(23,24)$. Although the United States does not have active national enterovirus surveillance, the enterovirus cases reported in 2 passive laboratory-based reporting systems (the National Enterovirus Surveillance System and the National Respiratory and Enteric Virus Surveillance System) demonstrate the presence of an annual enterovirus season with variation in the enterovirus types circulating each year $(23,25,26)$. Climate, level of immunity in the host population, and viral fitness probably influence which strains dominate each year (27). If $>1$ specific type of enterovirus causes AFM, differences in circulating types could account for changes in AFM epidemiology from year to year. EV-D68 might be one such type. Respiratory disease surveillance indicates that EV-D68 appears to have circulated in a biennial pattern since 2014, corresponding with trends in AFM. In 2014, 2016, and 2018, increase in respiratory disease caused by EV-D68 coincided with the increases in AFM (24,28-30). Since 2014, the correlation between EV-D68 circulation and AFM incidence has also been documented in Canada, Japan, Europe, and Argentina (31-34). Global collaborations for the investigation of AFM cases and ongoing, active enterovirus surveillance will enable a broader and more complete picture of enterovirus circulation patterns and their relationships to AFM in the future.

Sentinel surveillance of other enteroviruses, such as coxsackieviruses A2 and A4, have also demonstrated a biennial periodicity like that observed for EVD68 (35), although neither of these coxsackieviruses have been implicated in clusters of AFM. Rotavirus has also been shown to have a biennial circulation pattern in the postvaccination era (36). These biennial circulation patterns might be caused by an increase in the number of young, unexposed persons during years of low circulation, which leads to a larger number of susceptible persons acquiring and transmitting the infection in the following year. However, this phenomenon cannot fully explain the periodicity seen with AFM. The median age of AFM patients in peak years (5 years) is higher than the median age of patients with respiratory EV-D68 infections (3 years) (24), possibly indicating that other factors besides 
viral infection affect the risk for AFM development. Moreover, limited data show that persons across all age groups have robust neutralizing antibody titers against EV-D68 (37), including against both historical and contemporary outbreak strains, implying ongoing exposure and infection across the United States. The development of AFM in a small percentage of patients infected by this ubiquitous virus is likely to depend on other factors. Research into environmental or genetic risk factors for AFM development will provide insight into AFM pathogenesis.

Our findings are subject to limitations. First, differences in types of sterile and nonsterile specimens collected and sent to the CDC during 2015-2018 might have affected comparisons of enterovirus/rhinovirus positivity of cases in different years. However, because all enterovirus/rhinovirus-positive specimens were analyzed for enterovirus type, the percentage of typespecific (e.g., EV-D68 or EV-A71) cases among enterovirus/rhinovirus-positive cases would not have been affected. Second, we considered specimens enterovirus- or rhinovirus-positive only if the CDC laboratory confirmed this finding. Although CDC staff requested specimens for testing and confirmation, they might not have received all of them, thus influencing the results reported here. Last, the reporting of suspected cases to CDC public health staff is inconsistent, despite efforts to increase healthcare provider recognition of AFM. Year-to-year variation in reporting can occur, and more comprehensive reporting by healthcare providers might occur during peak years, when their awareness of this illness is heightened.

The alternate-year pattern in peak AFM activity since 2014 highlights a noteworthy shift in the epidemiology of this syndrome. Differences between AFM cases in peak years and nonpeak years provide additional evidence to support the hypothesis of a unique pathogen or pathogens contributing to this new epidemiology. Multiple lines of evidence support EV-D68 as a leading candidate, although additional research is needed. Frequent detection of EV-A71 in AFM cases in 2018 illustrates that $>1$ virus can cause outbreaks of AFM, and therefore AFM surveillance should not be restricted to detection of a specific pathogen. Healthcare providers thoroughly documenting clinical findings, including results of complete neurologic examinations, and reporting AFM cases to public health authorities, regardless of the pathogen implicated by test results, have implications for treatment and prevention. National AFM surveillance data can be used to characterize yearly variations in AFM cases (temporally, clinically, and etiologically) and illuminate the pathology of this emerging illness.

\section{Acknowledgments}

We thank the staff of state and local health departments, without whom this surveillance data would not have been collected. We thank our laboratory colleagues for providing enterovirus testing and typing data and Mary Ann Hall for her careful reading and editing of this manuscript.

\section{About the Author}

Mr. McLaren completed this work during a Student Worksite Experience Program internship in the Viral Vaccine Preventable Diseases Branch, Division of Viral Diseases, National Center for Immunization and Respiratory Diseases, CDC, in Atlanta, Georgia, USA, as a senior in high school at the Massachusetts Academy of Math and Science at Worcester Polytechnic Institute in Worchester, Massachusetts, USA. His primary research interests are neuroscience and infectious diseases.

\section{References}

1. Solomon T, Willison H. Infectious causes of acute flaccid paralysis. Curr Opin Infect Dis. 2003;16:375-81. https://doi.org/10.1097/00001432-200310000-00002

2. Ong KC, Wong KT. Understanding Enterovirus 71 neuropathogenesis and its impact on other neurotropic enteroviruses. Brain Pathol. 2015;25:614-24. https:/ / doi.org/ 10.1111/bpa.12279

3. Bitnun A, Yeh EA. Acute flaccid paralysis and enteroviral infections. Curr Infect Dis Rep. 2018;20:34. https:/ / doi.org/ 10.1007/s11908-018-0641-x

4. Saad M, Youssef S, Kirschke D, Shubair M, Haddadin D, Myers J, et al. Acute flaccid paralysis: the spectrum of a newly recognized complication of West Nile virus infection. J Infect. 2005;51:120-7. https://doi.org/10.1016/j.jinf.2004.10.005

5. Wang Y, Yu CY, Huang L, Han YY, Liu YM, Zhu J. Acute longitudinal and hemorrhagic myelitis caused by varicellazoster virus in an immunocompetent adolescent. Neurologist. 2015;19:93-5. https://doi.org/10.1097/ NRL.0000000000000016

6. Ivanova OE, Yurashko OV, Eremeeva TP, Baikova OY, Morozova NS, Lukashev AN. Adenovirus isolation rates in acute flaccid paralysis patients. J Med Virol. 2012;84:75-80. https://doi.org/10.1002/jmv.22265

7. Sejvar JJ, Bode AV, Marfin AA, Campbell GL, Ewing D, Mazowiecki M, et al. West Nile virus-associated flaccid paralysis. Emerg Infect Dis. 2005;11:1021-7. https:/ / doi.org/ 10.3201/eid1107.040991

8. Nathanson N. Eradication of poliomyelitis in the United States. Rev Infect Dis. 1982;4:940-50. https:/ / doi.org/ 10.1093/clinids/4.5.940

9. Nihei K, Naitoh H, Ikeda K. Poliomyelitis-like syndrome following asthmatic attack (Hopkins syndrome). Pediatr Neurol. 1987;3:166-8. https://doi.org/10.1016/0887-8994 (87)90085-3

10. Pastula DM, Aliabadi N, Haynes AK, Messacar K, Schreiner T, Maloney J, et al.; Centers for Disease Control and Prevention. Acute neurologic illness of unknown etiology in children - Colorado, August-September 2014. MMWR Morb Mortal Wkly Rep. 2014;63:901-2.

11. Centers for Disease Control and Prevention. AFM cases in U.S. [cited 2018 Nov 8]. https:/ / www.cdc.gov/ acute-flaccid-myelitis/cases-in-us.html 
12. Van Haren K, Ayscue P, Waubant E, Clayton A, Sheriff H, Yagi S, et al. Acute flaccid myelitis of unknown etiology in California, 2012-2015. JAMA. 2015;314:2663-71. https://doi.org/10.1001/jama.2015.17275

13. Messacar K, Schreiner TL, Maloney JA, Wallace A, Ludke J, Oberste MS, et al. A cluster of acute flaccid paralysis and cranial nerve dysfunction temporally associated with an outbreak of enterovirus D68 in children in Colorado, USA. Lancet. 2015;385:1662-71. https://doi.org/10.1016/ S0140-6736(14)62457-0

14. Uprety P, Curtis D, Elkan M, Fink J, Rajagopalan R, Zhao C, et al. Association of enterovirus D68 with acute flaccid myelitis, Philadelphia, Pennsylvania, USA, 2009-2018. Emerg Infect Dis. 2019;25:1676-82. https://doi.org/10.3201/ eid2509.190468

15. Messacar KS, Spence-Davizon E, Osborne C, Press C, Schreiner TL, Martin J, et al. Clinical characteristics of enterovirus A71 neurological disease during an outbreak in children in Colorado, USA, in 2018: an observational cohort study. Lancet Infect Dis. Online December 16, 2019. http:/ / dx.doi.org/10.1016/S1473-3099(19)30632-2

16. Pray LG. Observations on a poliomyelitis outbreak in North Dakota in 1946; with special consideration of spinal fluid findings. J Lancet. 1947;67:202-5.

17. Council of State and Territorial Epidemiologists. Revision to the standardized surveillance and case definition for acute flaccid myelitis. 2017 [cited 2018 Nov 8]. https:/ /cdn. ymaws.com/www.cste.org/resource/resmgr/2017PS/ 2017PSFinal/17-ID-01.pdf

18. Lopez A, Lee A, Guo A, Konopka-Anstadt JL, Nisler A, Rogers SL, et al. Vital signs: surveillance for acute flaccid myelitis - United States, 2018. MMWR Morb Mortal Wkly Rep. 2019;68:608-14. https://doi.org/10.15585/ mmwr.mm6827e1

19. Ayers T, Lopez A, Lee A, Kambhampati A, Nix WA, Henderson E, et al. Acute flaccid myelitis in the United States: 2015-2017. Pediatrics. 2019;144:e20191619. https://doi.org/10.1542/peds.2019-1619

20. Sejvar JJ, Lopez AS, Cortese MM, Leshem E, Pastula DM, Miller L, et al. Acute flaccid myelitis in the United States, August-December 2014: results of nationwide surveillance. Clin Infect Dis. 2016;63:737-45. https:// doi.org/10.1093/ cid/ciw372

21. Messacar K, Asturias EJ, Hixon AM, Van Leer-Buter C, Niesters HGM, Tyler KL, et al. Enterovirus D68 and acute flaccid myelitis-evaluating the evidence for causality. Lancet Infect Dis. 2018;18:e239-47. https://doi.org/10.1016/ S1473-3099(18)30094-X

22. Mishra N, Ng TFF, Marine RL, Jain K, Ng J, Thakkar R, et al. Antibodies to enteroviruses in cerebrospinal fluid of patients with acute flaccid myelitis. MBio. 2019;10:e01903-19. https://doi.org/10.1128/mBio.01903-19

23. Khetsuriani N, Lamonte-Fowlkes A, Oberst S, Pallansch MA; Centers for Disease Control and Prevention. Enterovirus surveillance-United States, 1970-2005. MMWR Surveill Summ. 2006;55:1-20.

24. Midgley CM, Watson JT, Nix WA, Curns AT, Rogers SL, Brown BA, et al.; EV-D68 Working Group. Severe respiratory illness associated with a nationwide outbreak of enterovirus D68 in the USA (2014): a descriptive epidemiological investigation. Lancet Respir Med. 2015;3:879-87. https://doi.org/10.1016/S2213-2600(15)00335-5

25. Abedi GR, Watson JT, Pham H, Nix WA, Oberste MS, Gerber SI. Enterovirus and human parechovirus surveillance - United States, 2009-2013. MMWR Morb Mortal Wkly Rep. 2015;64:940-3. https://doi.org/10.15585/mmwr.mm6434a3
26. Abedi GR, Watson JT, Nix WA, Oberste MS, Gerber SI. Enterovirus and parechovirus surveillance - United States, 2014-2016. MMWR Morb Mortal Wkly Rep. 2018;67:515-8. https://doi.org/10.15585/mmwr.mm6718a2

27. Pons-Salort M, Oberste MS, Pallansch MA, Abedi GR, Takahashi S, Grenfell BT, et al. The seasonality of nonpolio enteroviruses in the United States: patterns and drivers. Proc Natl Acad Sci U S A. 2018;115:3078-83. https:/ / doi.org/ 10.1073/pnas.1721159115

28. Messacar K, Robinson CC, Pretty K, Yuan J, Dominguez SR. Surveillance for enterovirus D68 in Colorado children reveals continued circulation. J Clin Virol. 2017;92:39-41. http://dx.doi.org/10.1016/j.jcv.2017.05.009

29. Naccache S, Bender J, Desai J, Van T, Meyers L, Jones J, et al. Acute flaccid myelitis cases presenting during a spike in respiratory enterovirus D68 circulation: case series from a single pediatric referral center. Open Forum Infect Dis. 2017;4(suppl_1):S305-6. https://doi.org/10.1093/ofid/ of 163.708

30. Kujawski SA, Midgley CM, Rha B, Lively JY, Nix WA, Curns AT, et al. Enterovirus D68-associated acute respiratory illness - new vaccine surveillance network, United States, July-October, 2017 and 2018. MMWR Morb Mortal Wkly Rep. 2019;68:277-80. https:/ / doi.org/ 10.15585/mmwr.mm6812a1

31. Skowronski DM, Chambers C, Sabaiduc S, Murti M, Gustafson R, Pollock S, et al. Systematic community- and hospital-based surveillance for enterovirus-D68 in three Canadian provinces, August to December 2014. Euro Surveill. 2015;20:30047. https://doi.org/10.2807/1560-7917. ES.2015.20.43.30047

32. Hatayama K, Goto S, Yashiro M, Mori H, Fujimoto T, Hanaoka N, et al. Acute flaccid myelitis associated with enterovirus D68 in a non-epidemic setting. IDCases. 2019;17:e00549. https://doi.org/10.1016/j.idcr.2019.e00549

33. Knoester M, Helfferich J, Poelman R, Van Leer-Buter C, Brouwer OF, Niesters HGM; 2016 EV-D68 AFM Working Group. Twenty-nine cases of enterovirus-D68-associated acute flaccid myelitis in Europe 2016: a case series and epidemiologic overview. Pediatr Infect Dis J. 2019;38:16-21. https:// doi.org/10.1097/INF.0000000000002188

34. Ruggieri V, Paz MI, Peretti MG, Rugilo C, Bologna R, Freire C, et al. Enterovirus D68 infection in a cluster of children with acute flaccid myelitis, Buenos Aires, Argentina, 2016. Eur J Paediatr Neurol. 2017;21:884-90. http:/ / dx.doi.org/10.1016/j.ejpn.2017.07.008

35. Pons-Salort M, Grassly NC. Serotype-specific immunity explains the incidence of diseases caused by human enteroviruses. Science. 2018;361:800-3. https://doi.org/ $10.1126 /$ science.aat6777

36. Hallowell BD, Parashar UD, Curns A, DeGroote NP, Tate JE. Trends in the laboratory detection of rotavirus before and after implementation of routine rotavirus vaccination - United States, 2000-2018. MMWR Morb Mortal Wkly Rep. 2019;68:539-43. https://doi.org/10.15585/ mmwr.mm6824a2

37. Harrison CJ, Weldon WC, Pahud BA, Jackson MA, Oberste MS, Selvarangan R. Neutralizing antibody against enterovirus D68 in children and adults before 2014 outbreak, Kansas City, Missouri, USA. Emerg Infect Dis. 2019;25:585-8. http://dx.doi.org/10.3201/eid2503.180960

Address for correspondence: Janell A. Routh, Centers for Disease Control and Prevention, 1600 Clifton Rd NE, Mailstop H24-5, Atlanta, GA 30329-4027, USA; email: iyp1@cdc.gov 